CLINICAL STUDY

\title{
Clustering of additional autoimmunity behaves differently in Hashimoto's patients compared with Graves' patients
}

\author{
J Wiebolt, R Achterbergh, A den Boer, S van der Leij, E Marsch, B Suelmann, R de Vries and T W van Haeften \\ Department of Endocrinology/Diabetology, University Medical Centre Utrecht and University of Utrecht, L00.407, Heidelberglaan 100, NL 3584 CX \\ Utrecht, The Netherlands
}

(Correspondence should be addressed to J Wiebolt; Email: j.wiebolt@umcutrecht.nl)

\begin{abstract}
Objective: It is unclear whether Hashimoto's thyroiditis and Graves' disease (often referred to as autoimmune thyroid disease, AITD) cluster to the same extent with other autoimmune disorders. Methods: We assessed adrenal, $\beta$-cell, celiac and gastric antibodies in a cohort of 523 adult patients with Graves' disease and 359 patients with Hashimoto's disease and compared their clustering.

Results: Adrenal autoimmunity associated more often with Hashimoto's disease (9.0\%) than with Graves' disease $(3.3 \%, P=0.001)$. $\beta$-cell autoimmunity was seen more frequently in Hashimoto's disease $(25.4 \%)$ than in Graves' disease $(15.6 \%, P=0.001)$ patients. We found low prevalences of celiac autoimmunity (1.2\% for Graves' and 1.2\% for Hashimoto's disease). Celiac and gastric autoimmunity were not statistically different in Hashimoto's and Graves' disease patients. Although gastric autoimmunity itself was equally prevalent (around 20\%), Hashimoto's disease often showed significantly more clustering of adrenal autoimmunity with gastric autoimmunity (5.3\%) than Graves' disease $(1.2 \%, P=0.001)$. Similarly, clustering of adrenal autoimmunity was seen with $\beta$-cell autoimmunity in Hashimoto's patients (3.2\%), while such clustering was much less encountered in 359 Graves' patients $(0.9 \%, P=0.029)$.

Conclusion: In conclusion, Hashimoto's disease shows a markedly higher clustering of additional autoimmunity, especially with adrenal and $\beta$-cell autoimmunity. Combined clustering of gastric and adrenal autoimmunity and combined clustering of adrenal and $\beta$-cell autoimmunity were both seen more often in Hashimoto's patients. Clustering with celiac disease appears to be low. These findings indicate that Hashimoto's and Graves' disease differ in their clinical expression regarding additional autoimmunity, which argues against the indiscriminate use of AITD as an entity.
\end{abstract}

European Journal of Endocrinology 164 789-794

\section{Introduction}

Autoimmune thyroid disease (AITD) includes Hashimoto's thyroiditis (goitrous or atrophic autoimmune thyroiditis) and Graves' disease. AITD has been proposed to be part of the autoimmune polyglandular syndromes (APS). In the original case report of 1926 , Schmidt described the autopsy reports of two patients with Addison's disease and Hashimoto's thyroiditis. Later, Neufeld et al. (1) classified the APS into distinct syndromes, e.g. APS-1 consisting of primary adrenal failure with chronic mucocutaneous candidiasis and/ or acquired hypoparathyroidism, APS-2 comprising primary adrenal failure, AITD and/or type 1 diabetes. By then, Graves' disease was also included into the classification by introducing the term 'AITD'. In a study of 107 patients with Addison's disease, Betterle \& Zanchetta (2) reported the occurrence of AITD in $82 \%$ of patients, $50 \%$ of whom had Addison's and Hashimoto's, 21\% had Addison's and Graves' and $11 \%$ had Addison's, AITD and type 1 diabetes.
This difference in clustering frequencies may indicate that Hashimoto's and Graves' disease do not have the same pathogenetic basis.

Although Graves' and Hashimoto's disease share several gene polymorphisms in CTLA4 (3), other CTLA4-gene polymorphisms tend to be more associated with Graves' disease (4). Furthermore, a recent study on Hashimoto's thyroiditis has demonstrated differences in HLA class II associations compared with Graves' disease (5).

Additional definitions of APS have been suggested since APS encompasses a wide clinical spectrum of disease with a highly variable presentation of the first manifestation. Also, the age of first presentation can be anywhere between infancy and late adult life. Neufeld et al. (1) defined APS-3 as the association between AITD with one of the following: DM1, atrophic gastritis or vitiligo, alopecia, myasthenia gravis or other organ-specific autoimmune disorders. Currently, relationship of autoimmune thyroid disorders with 
other organ-specific autoimmune disorders, such as Addison's disease, type 1 diabetes mellitus, pernicious anemia, celiac disease, dermatitis herpetiformis, multiple sclerosis, rheumatoid arthritis, systemic lupus erythematosus (SLE), systemic sclerosis and vitiligo, is well established $(6,7)$. Disease association with, for example, autoimmune hepatitis, primary biliary sclerosis and Sjögren's syndrome seems possible but require further confirmation (6). Similarly, type 1 diabetes predisposes to other organ-specific autoimmune disorders, such as AITD, Addison's disease, celiac disease and atrophic gastritis (8). APS-4 has been proposed to include all the clinical combinations which could not be allocated to one of the other three APS syndromes. Various authors (8-10), as well as the NICE guidelines, have concluded that preclinical screening for autoantibodies should be performed not only in patients with type 1 diabetes but also in patients with AITD $(11,12)$.

We asked the question whether differences exist in association with other autoimmune antibodies and/or disorders between Graves' disease and Hashimoto's disease. We undertook to compare adrenal, $\beta$-cell, celiac and gastric antibodies in a large cohort of adult patients with Hashimoto's or Graves' disease, in whom various autoantibodies were screened. We report here that patients with Hashimoto's disease show more often adrenal and $\beta$-cell autoimmunity than Graves' disease patients. Similarly, our patients with Hashimoto's thyroiditis show a clear clustering of adrenal autoimmunity with gastric autoimmunity, which was not apparent in Graves' disease patients. Surprisingly, both patient groups had a low prevalence of celiac autoimmunity.

The differences in clustering of additional autoimmune phenomena between these disorders may indicate that they should not be taken as to possess identical predisposition to other autoimmune disorders.

\section{Subjects and methods}

\section{Subjects}

Since 2005, 882 Caucasian patients treated for AITD at the outpatient clinic of the Department of Endocrinology-Diabetology of the University Medical Centre in Utrecht (UMCU), The Netherlands, have been screened routinely for the presence of other autoimmune antibodies. AITD included Hashimoto's disease (goitrous or atrophic autoimmune hypothyroidism), defined as (sub)clinical hypothyroidism in combination with thyroid peroxidase (TPO)-antibodies, and Graves' disease (autoimmune hyperthyroidism), defined as clinical hyperthyroidism in combination with positive thyroid-stimulating immunoglobulins. From the same outpatient clinic of the Department of EndocrinologyDiabetology, we included Addison's disease patients only if the diagnosis of AITD was made prior to or together with the diagnosis of Addison's disease in order to rule out selection bias; our department has no specific Addison's outpatient clinic. Patients with Down syndrome or Turner's syndrome were excluded.

At the time of diagnosis or during follow-up, patients were routinely screened for the presence of autoimmune antibodies: antibodies against TPO, parietal cell antibodies (APC), intrinsic factor (IF) antibodies, tissue transglutaminase antibodies (TTG), endomysium antibodies (Em), adrenal cortex (AC) antibodies and glutamic acid decarboxylase (GAD). IgA immunoglobulin levels were measured to rule out IgA deficiency. Also, plasma vitamin B12 level, homocystein, free thyroxine and TSH levels were routinely determined.

\section{Methods}

A luminescence immunoassay (human LIA, BRAHMS, Henningsdorf, Germany) was used for the quantitative determination of antibodies against TPO and the human TSH receptor. Values of more than $60 \mathrm{U} / \mathrm{ml}$ and $1.5 \mathrm{IU} / \mathrm{l}$ respectively, were regarded as positive. The sensitivity and specificity for anti-TPO assessments were 89 and $90 \%$ respectively, and 98.8 and $99.6 \%$ respectively, for the anti-TSH assessment.

ELISA (Euroimmun, Lübeck, Germany) was applied for anti-IF (positive value $\geq 20 \mathrm{U} / \mathrm{ml}$ ), sera dilution: 1:100 sample buffer, anti-TTG (positive value $\geq 10 \mathrm{U} / \mathrm{ml}$ ), sera dilution: 1:100 sample buffer and anti-GAD (positive value $\geq 10 \mathrm{IU} / \mathrm{l}$ ), undiluted. The sensitivity and specificity for these tests were 100 and $100 \%$ for the anti-IF test, 96.2 and $99.4 \%$ for anti-TTG and 92 and $98 \%$ for anti-GAD. All antibody parameters were reported as present or absent. Dubious or weak diagnostic findings were considered as absent antibodies.

An indirect immunofluorescence assay (IFA) was used for screening for circulating antibodies to parietal cells, endomysium (Euroimmun) and the AC (The Binding Site Ltd, Birmingham, UK), with a sensitivity and specificity of 95 and $98 \%$ for APC antibodies, 91 and $98 \%$ for anti-Em and 95 and 95\% for anti-AC. Substrates used were monkey esophagus and monkey adrenal. All antibody parameters were reported as present or absent. Dubious or weak diagnostic findings were considered as absent antibodies, to rule out uncertainty.

\section{Assessment}

At the time of diagnosis and during follow-up, patients were assessed regarding the presence of other autoimmune diseases, primarily for Addison's disease, type 1 diabetes mellitus, celiac disease, atrophic gastritis, pernicious anemia or vitamin B12 deficiency (without specific cause such as use of metformin, alcohol or celiac disease). In the absence of clinical disease, patients with positive antibodies were screened for the presence of 
(sub) clinical disease once every year; for example, in patients with adrenal antibodies, basal ACTH levels were measured and an ACTH stimulation test was performed. For patients with positive anti-GAD antibodies, a fasting plasma glucose was measured. In patients with positive APC and/or anti-IF, vitamin B12 levels were measured yearly. The decision to perform gastroscopy in patients with positive APC or with positive Em and TTG antibodies was left to the discretion of the attending physician.

We defined patients as being prone to autoimmunity when they had either another clinical autoimmune disease or had an associated antibody. We defined four categories:

i. Adrenal autoimmunity was defined as presence of Addison's disease and/or AC antibodies. Addison's disease (adrenal insufficiency) was diagnosed on the basis of a combination of low serum cortisol levels and strong elevations in plasma ACTH or on the basis of an abnormal ACTH stimulation test.

ii. $\beta$-cell autoimmunity was defined as type 1 diabetes mellitus or positivity for anti-GAD antibodies in patients without type 1 diabetes. Celiac autoimmunity was considered to be present in patients who had biopsy-proven celiac disease or who were positive for both Em and TTG antibodies.

iii. Gastric autoimmunity was considered to be present if patients were positive for at least one of the following: APC antibodies, anti-IF antibodies, signs of atrophic gastritis at gastroscopy, pernicious anemia or low vitamin B12 level ( $<130 \mathrm{pmol} / \mathrm{l})$, without a specific cause such as use of metformin, alcohol, or celiac disease. Patients in whom a specific cause for vitamin B12 deficiency other than gastric autoimmunity was suspected were not included as having a low vitamin B12 level.

iv. Other additional autoimmune diseases were looked for in the patients' medical files; vitiligo, alopecia, psoriasis, myasthenia gravis, multiple sclerosis, Crohn's disease, ulcerative colitis, autoimmune hepatitis, primary biliary cirrhosis, primary sclerosing cholangitis, SLE, rheumatoid arthritis, Sjogren's disease, scleroderma (dermato) myositis, idiopathic thrombocytopenia, premature ovarian failure and autoimmune hypoparathyroidism. If one or more of these disorders were present, the cases were defined as Other autoimmune disease.

\section{Statistical analysis}

For statistical analysis, SPSS, version 15 (IBM Company, Chicago, IL, USA) was used. Group comparisons were performed by the use of the $\chi^{2}$ test. Odds ratio (OR) and the $95 \%$ confidence interval $(95 \% \mathrm{CI})$ were used to investigate differences between the groups and clustering of the various autoimmune antibodies. When sample sizes were small (i.e. below 5), Fisher's exact test was used. $P<0.05$ was considered statistically significant.

\section{Results}

A total of 882 Caucasian patients consisted of 523 patients with Graves' disease and 359 patients with Hashimoto's thyroiditis (Table 1).

\section{Adrenal autoimmunity}

Addison's disease was significantly more prevalent in Hashimoto's disease than in Graves' disease (5.3 and $1.7 \%$ respectively, $P=0.03$; OR 3.19 , 95\% CI $1.43-$ 7.14) (Table 2). There was no difference in gender distribution. All together, adrenal autoimmunity was three times more prevalent in Hashimoto's disease than in Graves' disease $(P=0.001$, Tables 2 and 3).

\section{$\beta$-cell autoimmunity}

Type 1 diabetes was more prevalent in Hashimoto's disease than in Graves' disease (15.9 and 9.2\% respectively, $P=0.03)$. In Hashimoto's disease, $6.6 \%$ of patients without type 1 diabetes were GAD-positive compared with $4.6 \%$ of non-diabetic patients with Graves' disease $(P=0.29)$. $\beta$-Cell autoimmunity was significantly more prevalent in Hashimoto's disease $(25.4 \%)$ than in Graves' disease (15.6\%, $P=0.001$; OR $1.84,95 \%$ CI 1.26-2.68).

\section{Celiac autoimmunity}

There was no difference in celiac disease, anti-TTG and anti-Em antibodies or celiac autoimmunity between Hashimoto's and Graves' disease. Remarkably, none of the 60 men with Graves' disease showed celiac autoimmunity.

\section{Gastric autoimmunity}

Vitamin B12 deficiency (i.e. plasma vitamin B12 below $130 \mathrm{pmol} / \mathrm{l}$, without a specific cause other than gastric autoimmunity) was encountered in a substantial number of subjects (66 in total). Patients positive for antibodies against parietal cells or IF, without B12 deficiency, were

Table 1 Biographics of subjects with AITD (mean \pm s.D.).

\begin{tabular}{lll}
\hline & Graves' disease & Hashimoto's disease \\
\hline$n$ & 523 & 359 \\
Gender (F/M) & $444 / 79$ & $307 / 52$ \\
Age (years) & $50.0 \pm 14.0$ & $49.0 \pm 15.0$ \\
Duration of & $12.0 \pm 10.0$ & $10.0 \pm 8.0$ \\
disease (years) & & \\
\hline
\end{tabular}


Table 2 Additional autoimmunity (adrenal, $\beta$-cell, celiac, gastric and 'other') in Graves' $(n=523)$ and Hashimoto's $(n=359)$ disease patients. For each entity, 'total' cases is given, followed by subdivision into categories of patients with clinical disease and patients with autoantibodies without clinical disease.

\begin{tabular}{|c|c|c|}
\hline & $\begin{array}{c}\text { Graves' } \\
\text { No. of cases/ } \\
\text { total cases } \\
\text { measured }(\%)\end{array}$ & $\begin{array}{c}\text { Hashimoto's } \\
\text { No. of cases/ } \\
\text { total cases } \\
\text { measured }(\%)\end{array}$ \\
\hline Adrenal autoimmunity (total) & $14 / 421(3.3)$ & $25 / 278(9.0)$ \\
\hline Addison's disease & 9/523 (1.7) & 19/359 (5.3) \\
\hline $\begin{array}{l}\text { Adrenal antibodies without } \\
\text { Addison's }\end{array}$ & $5 / 412(1.2)$ & $6 / 259(2.3)$ \\
\hline$\beta$-Cell autoimmunity (total) & $65 / 417(15.6)$ & $72 / 284(25.4)$ \\
\hline Diabetes type 1 & $48 / 523(9.2)$ & $57 / 359(15.9)$ \\
\hline $\begin{array}{l}\text { GAD antibodies without } \\
\text { diabetes }\end{array}$ & $17 / 369(4.6)$ & $15 / 227(6.6)$ \\
\hline Celiac autoimmunity (total) & $5 / 411(1.2)$ & $3 / 260(1.2)$ \\
\hline Celiac disease & $2 / 523(0.4)$ & 2/359 (0.6) \\
\hline $\begin{array}{l}\text { Anti-TTG and anti-Em } \\
\text { without histology }\end{array}$ & $3 / 414(0.7)$ & $1 / 263(0.4)$ \\
\hline Gastric autoimmunity (total) & 75/391 (19.2) & $64 / 273(23.4)$ \\
\hline $\begin{array}{l}\text { Vitamin B12 deficiency or } \\
\text { atrophic gastritis }\end{array}$ & $36 / 436(8.3)$ & $30 / 310(9.7)$ \\
\hline $\begin{array}{l}\text { APC or IF without vitamin } \\
\text { B12 deficiency }\end{array}$ & 39/355 (11.0) & $34 / 243(14.0)$ \\
\hline Other autoimmune diseases & $34 / 523(6.5)$ & $43 / 359(12.0)$ \\
\hline
\end{tabular}

often seen in patients with Graves' (10.2\%) and Hashimoto's disease (13.5\%). There were no significant differences in gastric autoimmunity (23.4 and 19.2\%) between Hashimoto's and Graves' disease patients.

\section{Other autoimmune diseases}

Combined, these diseases were seen more often in Hashimoto's disease than in Graves' disease (12.0 and $6.5 \%, P=0.05$; OR 1.96, 95\% CI 1.22-3.14). Since these disorders were each present in $<1 \%$, we did not look for clustering of each particular disease with Hashimoto's or Graves' disease.

\section{Clustering of additional autoimmunity}

Since clustering of autoimmunity is the hallmark of APS, we looked into detail at the various forms of clusters in Hashimoto's disease and Graves' disease patients.

In Table 4, the prevalences of the various clusters of additional autoimmunity are shown. The combination of adrenal and $\beta$-cell autoimmunity was seen more often (OR 3.47, 95\% CI 1.06-11.37; $P=0.029$ ) in patients with Hashimoto's disease $(3.2 \%)$, compared with patients with Graves' disease $(0.9 \%)$. If type 1 diabetes patients were excluded, 5 of 234 Hashimoto's disease patients were found adrenal and GAD positive and none of 383 patients with Graves' disease, with even more stringent statistical significance $(P=0.008$, Fisher's exact test). Furthermore, the combination of adrenal and gastric autoimmunity was also more often present in Hashimoto's disease than in Graves' disease (OR 4.70, 95\% CI 1.69-13.09; $P=0.001$ ). Within the Hashimoto's subgroup, patients positive for gastric autoimmunity showed over five times more adrenal autoimmunity than gastric autoimmunity-negative patients $\left(28.6\right.$ vs $\left.5.1 \% ; \chi^{2}=21.60 ; P<0.0005\right)$. Within the Graves' disease patients, this relationship was not seen $(5.6$ vs $2.1 \%$ respectively, $P=0.16$, Fisher's exact test). All other potential cluster combinations showed no significant differences. Notably, among our small group of celiac autoimmunity-positive patients, no (concurrent) adrenal autoimmunity was found and only three patients had concomitantly gastric and celiac autoimmunity.

\section{Discussion}

We undertook to compare adrenal, $\beta$-cell, celiac and gastric antibodies in a cohort of adult patients with Hashimoto's or Graves' disease in order to compare clustering of autoimmune manifestations between these thyroid diseases. This study shows that patients with Hashimoto's disease are two- to three-fold more at risk for adrenal antibodies and adrenal autoimmunity than patients with Graves' disease. Although gastric autoimmunity itself was equally prevalent in Hashimoto's and Graves' disease, Hashimoto's disease showed a clear clustering of adrenal autoimmunity with gastric autoimmunity, which was much less apparent (and was not statistically significant) in Graves' disease. Similarly, clustering of adrenal autoimmunity with $\beta$-cell autoimmunity was seen in diabetic (9/281) as well as in non-diabetic (5/234) Hashimoto's disease patients, while such clustering was not encountered in 383 non-diabetic Graves' disease patients. Finally, we found relatively low prevalence of celiac autoimmunity in each of the two thyroid disorders.

In thyroid patients (Graves' disease or Hashimoto's disease), the frequency of adrenal antibodies has been reported to be around 2-3\% (13-15). Studies comparing additional autoimmunity in Graves' and Hashimoto's disease in sufficient numbers of patients

Table 3 Adrenal, $\beta$-cell, celiac and gastric autoimmunity in Hashimoto's vs Graves' disease.

\begin{tabular}{|c|c|c|c|}
\hline $\begin{array}{l}\text { Auto- } \\
\text { immunity }\end{array}$ & $\begin{array}{l}\text { Hashimoto's vs Graves' } \\
\text { (No. of cases/ } \\
\text { total cases assessed) }\end{array}$ & OR (95\% Cl) & $P$ value \\
\hline Adrenal & $\begin{array}{c}25 / 278 \text { vs } 14 / 421 \\
(9.0 \text { vs } 3.3 \%)\end{array}$ & $2.87(1.47-5.63)$ & 0.001 \\
\hline$\beta$-Cell & $\begin{array}{r}72 / 284 \text { vs } 65 / 417 \\
(25.4 \text { vs } 15.6 \%)\end{array}$ & $1.84(1.26-2.68)$ & 0.001 \\
\hline Celiac & $\begin{array}{l}3 / 260 \text { vs } 5 / 411 \\
(1.2 \text { vs } 1.2 \%)\end{array}$ & $0.95(0.23-4.00)$ & NS \\
\hline Gastric & $\begin{array}{r}64 / 273 \text { vs } 75 / 391 \\
(23.4 \text { vs } 19.2 \%)\end{array}$ & $1.27(0.88-1.85)$ & NS \\
\hline
\end{tabular}

OR, odds ratio; $95 \% \mathrm{Cl}, 95 \%$ confidence interval; NS, not significant. 
Table 4 Clustering of combinations of adrenal, $\beta$-cell, celiac and gastric autoimmunity in Hashimoto's vs Graves' disease.

\begin{tabular}{lllllll}
\hline & $\begin{array}{l}\text { Adrenal and } \\
\boldsymbol{\beta} \text {-cell }\end{array}$ & $\begin{array}{l}\text { Adrenal and } \\
\text { celiac }\end{array}$ & $\begin{array}{l}\text { Adrenal and } \\
\text { gastric }\end{array}$ & $\begin{array}{l}\boldsymbol{\beta} \text {-cell and } \\
\text { celiac }\end{array}$ & $\begin{array}{l}\boldsymbol{\beta} \text {-cell and } \\
\text { gastric }\end{array}$ & $\begin{array}{l}\text { Celiac and } \\
\text { gastric }\end{array}$ \\
\hline Hashimoto's & $9 / 281(3.2 \%)$ & $0 / 285(0 \%)$ & $15 / 283(5.3 \%)$ & $1 / 281(0.4 \%)$ & $21 / 282(7.4 \%)$ & $2 / 279(0.7 \%)$ \\
Graves' & $4 / 423(0.9 \%)$ & $0 / 431(0 \%)$ & $5 / 425(1.2 \%)$ & $0 / 424(0 \%)$ & $18 / 412(4.4 \%)$ & $1 / 424(0.2 \%)$ \\
OR $(95 \% \mathrm{Cl})$ & $3.47(1.06-11.37)$ & NA & $4.70(1.69-13.09)$ & NA & $1.76(0.92-3.37)$ & $3.05(0.28-33.84)$ \\
$P$ value & 0.029 & NA & 0.001 & NS & NS & NS \\
\hline
\end{tabular}

NA, not applicable due to zero events; NS, not significant.

are clearly very scarce. We report here prevalences of adrenal autoimmunity (AC antibodies and/or Addison's disease) in two large groups of Graves' disease and Hashimoto's patients separately. We found an almost threefold higher occurrence of adrenal autoimmunity in Hashimoto's disease than in Graves' disease. Although the study by Boelaert et al. (16) also reported that Addison disease was more prevalently found in Hashimoto's disease (1.4\%) than in Graves' disease $(0.11 \%)$, the authors reported only clinical data without clarifying in what proportion of subjects (if any) antibodies were actually assessed. Their data may therefore represent a clear underestimation.

In our patients without type 1 diabetes, positive antiGAD antibodies were present in $6.6 \%$ of patients with Hashimoto's thyroiditis and in $4.6 \%$ of patients with Graves' disease, which was not significantly different. These results are comparable with studies previously reported (17-19). A Turkish study reported a prevalence of $5.1 \%$ GAD-positivity in 215 patients with Hashimoto's thyroiditis, which is a similar percentage as our finding of $6.6 \%$ (17). In Japanese studies, around $4 \%$ of Graves' patients and around 3-6\% of Hashimoto's patients were positive for GAD-antibodies $(18,19)$.

In the present cohort, type 1 diabetes was significantly more prevalent in Hashimoto's disease than in Graves' disease ( 15.9 vs $9.2 \%$ ), which is in line with the findings of other authors $(6,16)$.

We found equally low prevalences of celiac disease of $1.2 \%$ in Hashimoto's and Graves' disease. This is somewhat lower than recent (smaller) studies which reported percentages between 2.7 and 4.8 (20-23). We ruled out IgA-deficiency since Em and TTG test are an IgA-class test. Since most authors report around $0.5-1.0 \%$ celiac disease in the general population, this low prevalence would imply that the association of Graves' or Hashimoto's disease with celiac autoimmunity is at the most relatively weak.

In our study, $20 \%$ of both Hashimoto's and Graves' disease patients showed gastric autoimmunity, comparable to previous reports in adults (24), while in children, even higher percentages have been found (25). Moreover, we found a prevalence of vitamin B12 deficiency of 9.7 and 8.3\% in Hashimoto's and Graves' disease respectively. This is lower than the overall prevalence of $28 \%$ found in a previous study in a mix of 94 thyroid disease patients (26). Although the authors used the same reference range, unfortunately, they did not mention whether other causes (metformin, alcohol or celiac disease) had been excluded. In a study of 63 adult patients concordant for AITD and DM1, the prevalence of vitamin B12 deficiency due to atrophic gastritis was $6.3 \%(27)$, while in our present cohort, this percentage was $9.8 \%$ (10/102 patients).

A hallmark of the various APS entities is the clustering of a number of autoimmune disorders. Often, AITD is included in this clustering without differentiation between Hashimoto's and Graves' disease. We therefore wanted to further explore the various clustering in our Hashimoto's and Graves' disease patients. Remarkably, adrenal-gastric autoimmunity clustering was seen in $5.3 \%$ of our Hashimoto's disease patients and in only $1.2 \%$ of Graves' disease patients. Similarly, clustering of adrenal- $\beta$-cell autoimmunity was more often encountered in Hashimoto's disease (3.2\%) than in Graves' disease (0.9\%). Together, this may point to a predisposing effect of adrenal autoimmunity towards additional ( $\beta$-cell and/or gastric) autoimmunity mainly in Hashimoto's disease.

In summary, we assessed additional autoimmunity in a cohort of Graves' and Hashimoto's disease patients. Patients with Hashimoto's disease showed a two- to three-fold greater risk for adrenal antibodies and adrenal autoimmunity than patients with Graves' disease. Gastric autoimmunity was comparable in both disorders. Interestingly, Hashimoto's disease patients had a greater risk of both adrenal- $\beta$-cell and adrenal-gastric autoimmunity clustering. Finally, celiac disease was encountered in only about $1 \%$ of patients. In conclusion, although Hashimoto's and Graves' disease share a tendency toward gastric autoimmunity and a low prevalence of celiac disease, Hashimoto's disease shows a markedly higher clustering of additional autoimmunity, namely adrenal- $\beta$-cell and adrenal-gastric autoimmunity. These differences argue against the indiscriminate use of the term AITD, for example, in the delineation of APS.

\section{Declaration of interest}

The authors declare that there is no conflict of interest that could be perceived as prejudicing the impartiality of the research reported.

\section{Funding}

This research did not receive any specific grant from any funding agency in the public, commercial or not-for-profit sector. 


\section{References}

1 Neufeld M, Maclaren N \& Blizzard R. Autoimmune polyglandular syndromes. Pediatric Annals 19809 154-162.

2 Betterle C \& Zanchetta R. Update on autoimmune polyendocrine syndromes (APS). Acta Bio-Medica 2003 74 9-33.

3 Kavvoura FK, Akamizu T, Awata T, Ban Y, Chistiakov DA, Frydecka I, Ghaderi A, Gough SC, Hiromatsu Y, Ploski R, Wang PW, Ban Y, Bednarczuk T, Chistiakova EI, Chojm M, Heward JM, Hiratani H, Juo SH \& Karabon L. Cytotoxic T-lymphocyte associated antigen 4 gene polymorphisms and autoimmune thyroid disease: a meta-analysis. Journal of Clinical Endocrinology and Metabolism 200792 3162-3170. (doi:10. 1210/jc.2007-0147)

4 Ueda H, Howson JM, Esposito L, Heward J, Snook H, Chamberlain G, Rainbow DB, Hunter KM, Smith AN, Di GG, Herr MH, Dahlman I, Payne F, Smyth D, Lowe C, Twells RC, Howlett S, Healy B \& Nutland S. Association of the T-cell regulatory gene CTLA4 with susceptibility to autoimmune disease. Nature 2003423 506-511. (doi:10.1038/nature01621)

5 Zeitlin AA, Heward JM, Newby PR, Carr-Smith JD, Franklyn JA, Gough SC \& Simmonds MJ. Analysis of HLA class II genes in Hashimoto's thyroiditis reveals differences compared to Graves' disease. Genes and Immunity 20089 358-363. (doi:10.1038/gene. 2008.26)

6 Jenkins RC \& Weetman AP. Disease associations with autoimmune thyroid disease. Thyroid 200212 977-988. (doi:10. 1089/105072502320908312)

7 Wiebolt J, Koeleman BP \& van Haeften TW. Endocrine autoimmune disease: genetics become complex. European Journal of Clinical Investigation $2010401144-1155$. (doi:10.1111/j.13652362.2010.02366.x)

8 Liu E \& Eisenbarth GS. Type 1A diabetes mellitus-associated autoimmunity. Endocrinology and Metabolism Clinics of North America 200231 391-410. (doi:10.1016/S0889-8529(01) 00017-2)

9 de Graaff LC, Smit JW \& Radder JK. Prevalence and clinical significance of organ-specific autoantibodies in type 1 diabetes mellitus. Netherlands Journal of Medicine 200765 235-247.

10 Schatz DA \& Winter WE. Autoimmune polyglandular syndrome. II: Clinical syndrome and treatment. Endocrinology and Metabolism Clinics of North America 200231 339-352. (doi:10.1016/S08898529(01)00012-3)

11 Falorni A, Laureti S \& Santeusanio F. Autoantibodies in autoimmune polyendocrine syndrome type II. Endocrinology and Metabolism Clinics of North America 200231 369-389. (doi:10.1016/S0889-8529(01)00010-X)

12 Robles DT, Fain PR, Gottlieb PA \& Eisenbarth GS. The genetics of autoimmune polyendocrine syndrome type II. Endocrinology and Metabolism Clinics of North America 200231 353-368. (doi:10.1016/S0889-8529(01)00015-9)

13 Falorni A, Laureti S, Nikoshkov A, Picchio ML, Hallengren B, Vandewalle CL, Gorus FK, Tortoioli C, Luthman H, Brunetti P \& Santeusanio F. 21-Hydroxylase autoantibodies in adult patients with endocrine autoimmune diseases are highly specific for Addison's disease. Belgian Diabetes Registry. Clinical and Experimental Immunology 1997107 341-346. (doi:10.1111/j.13652249.1997.262-ce1153.x)

14 Scherbaum WA, Stockle G, Wichmann J \& Berg PA. Immunological and clinical characterization of patients with untreated euthyroid and hypothyroid autoimmune thyroiditis. Antibody spectrum, response to TRH and clinical study. Acta Endocrinologica 1982100 373-381. (doi:10.1530/acta.0.1000373)

15 Silva RC, Sallorenzo C, Kater CE, Dib SA \& Falorni A. Autoantibodies against glutamic acid decarboxylase and 21-hydroxylase in Brazilian patients with type 1 diabetes or autoimmune thyroid diseases. Diabetes, Nutrition and Metabolism 200316 60-168.

16 Boelaert K, Newby PR, Simmonds MJ, Holder RL, Carr-Smith JD, Heward JM, Manji N, Allahabadia A, Armitage M, Chatterjee KV, Lazarus JH, Pearce SH, Vaidya B, Gough SC \& Franklyn JA. Prevalence and relative risk of other autoimmune diseases in subjects with autoimmune thyroid disease. American Journal of Medicine 2010123 183-189. (doi:10.1016/j.amjmed. 2009.06.030)

17 Aksoy DY, Yurekli BP, Yildiz BO \& Gedik O. Prevalence of glutamic acid decarboxylase antibody positivity and its association with insulin secretion and sensitivity in autoimmune thyroid disease: a pilot study. Experimental and Clinical Endocrinology and Diabetes 2006114 412-416. (doi:10.1055/s-2006-924153)

18 Kawasaki E, Abiru N, Yano M, Uotani S, Matsumoto K, Matsuo H, Yamasaki H, Yamamoto $H$, Yamaguchi $Y$ \& Akazawa S. Autoantibodies to glutamic acid decarboxylase in patients with autoimmune thyroid disease: relation to competitive insulin autoantibodies. Journal of Autoimmunity 19958 633-643. (doi:10.1006/jaut.1995.0047)

19 Moriguchi M, Noso S, Kawabata Y, Yamauchi T, Harada T, Komaki K, Babaya N, Hiromine Y, Ito H, Yamagata S, Murata K, Higashimoto T, Park C, Yamamoto A, Ohno Y \& Ikegami H. Clinical and genetic characteristics of patients with autoimmune thyroid disease with anti-islet autoimmunity. Metabolism 2010. In press (doi:10.1016/j.metabol.2010.07.025)

20 Berti I, Trevisiol C, Tommasini A, Citta A, Neri E, Geatti O, Giammarini A, Ventura A \& Not T. Usefulness of screening program for celiac disease in autoimmune thyroiditis. Digestive Diseases and Sciences $2000 \mathbf{4 5}$ 403-406. (doi:10.1023/ A:1005441400107)

21 Volta U, Ravaglia G, Granito A, Forti P, Maioli F, Petrolini N, Zoli M \& Bianchi FB. Coeliac disease in patients with autoimmune thyroiditis. Digestion 200164 61-65. (doi:10.1159/000048840)

22 Hadithi M, Meijer JW, Willekens F, Kerckhaert JA, Heijmans R, Pena AS, Stehouwer CD \& Mulder CJ. Coeliac disease in Dutch patients with Hashimoto's thyroiditis and vice versa. World Journal of Gastroenterology 200713 1715-1722.

23 Ch'ng CL, Biswas M, Benton A, Jones MK \& Kingham JG Prospective screening for coeliac disease in patients with Graves' hyperthyroidism using anti-gliadin and tissue transglutaminase antibodies. Clinical Endocrinology 200562 303-306. (doi:10. $1111 / \mathrm{j} .1365-2265.2005 .02214 . \mathrm{x})$

24 Tozzoli R, Kodermaz G, Perosa AR, Tampoia M, Zucano A, Antico A \& Bizzaro N. Autoantibodies to parietal cells as predictors of atrophic body gastritis: a five-year prospective study in patients with autoimmune thyroid diseases. Autoimmunity Reviews 2010 10 80-83. (doi:10.1016/j.autrev.2010.08.006)

25 Segni M, Borrelli O, Pucarelli I, Delle FG, Pasquino AM \& Annibale B. Early manifestations of gastric autoimmunity in patients with juvenile autoimmune thyroid diseases. Journal of Clinical Endocrinology and Metabolism $2004894944-4948$. (doi:10.1210/jc.2003-031597)

26 Perros P, Singh RK, Ludlam CA \& Frier BM. Prevalence of pernicious anaemia in patients with type 1 diabetes mellitus and autoimmune thyroid disease. Diabetic Medicine 200017 749-751. (doi:10.1046/j.1464-5491.2000.00373.x)

27 Ness-Abramof R, Nabriski DA, Braverman LE, Shilo L, Weiss E, Reshef T, Shapiro MS \& Shenkman L. Prevalence and evaluation of B12 deficiency in patients with autoimmune thyroid disease. American Journal of the Medical Sciences 2006332 119-122. (doi:10.1097/00000441-200609000-00004)

Received 25 February 2011

Accepted 3 March 2011 